\title{
Monetary policy, asset prices, and uncertainty
}

\author{
Fernando Alexandre ${ }^{\mathrm{a}, *}$, Pedro Bação ${ }^{\mathrm{b}}$ \\ ${ }^{a}$ Birkbeck College and NIPE, University of Minho, Portugal \\ ${ }^{\mathrm{b}}$ Faculty of Economics, Birkbeck College and GEMF, University of Coimbra, Portugal
}

Received 29 February 2004; accepted 17 June 2004

Available online 29 September 2004

\begin{abstract}
We show that the benefits from reacting to misalignments in asset prices may disappear when there is noise in the variables to which the monetary policy instrument responds, and this noise is positively correlated across variables.

(C) 2004 Elsevier B.V. All rights reserved.

Keywords: Monetary policy; Asset prices; Uncertainty

JEL classification: E52; E58
\end{abstract}

\section{Introduction}

Cecchetti et al. (2000) presented the view that monetary policy rules should be augmented with a reaction to misalignments in asset prices. The reaction coefficient should be positive to have a countercyclical impact and also to discourage misalignments. Because estimation of misalignments in asset prices is far from trivial, some authors (e.g., Bernanke and Gertler, 1999) have argued that reacting to estimated misalignments is a dangerous thing to do and could actually be destabilising. The counterargument of Cecchetti et al. (2000) is that if it is the case that asset prices do affect the economy's path,

* Corresponding author. Departamento de Economia, Escola de Economia e Gestão, Universidade do Minho, Campus de Gualtar, 4710-Braga, Portugal. Tel.: +351 253 604510; fax: +351 253676375.

E-mail address: falex@eeg.uminho.pt (F. Alexandre). 
then estimation of the other typical elements in a policy rule (usually, the output gap and inflation expectations) will have to rely on some estimate of the evolution of asset prices. Therefore, estimates of misalignments are already being used, although implicitly, in monetary policy decisions. The counterargument then concludes that difficulties in estimating misalignments should not deter policymakers from introducing them in the policy rule.

Our contention is that this counter-argument is not necessarily valid. The counter-argument implies that there should be a positive correlation between the errors in the estimation of the different elements of a typical policy rule, because we would expect the output gap and inflation to be higher (lower) than expected when asset prices are also higher (lower) than expected. We show that if this is the case, then the benefits from reacting with a positive coefficient to asset prices may vanish, thus weakening the case for reacting to asset prices. We do this in the context of a linear rational expectations model. The basis of the model (of the New Keynesian variety) is nowadays common in the literature. We therefore motivate the model only briefly and provide the reader with alternative references. The intuition for our result is that if the estimation errors are positively correlated, reacting to both inflation and misalignments with a positive coefficient increases the impact of those errors.

\section{A stylised macroeconomic model with asset prices}

Our stylised system of macroeconomic equations is the following:

$$
\begin{aligned}
& y_{t}=E_{t} y_{t+1}-\alpha_{1}\left(i_{t}-E_{t} \pi_{t+1}\right)+\alpha_{2} A_{t}+\varepsilon_{t}^{\mathrm{d}} \\
& \pi_{t}=\beta_{1} \pi_{t-1}+\left(1-\beta_{1}\right) \beta E_{t} \pi_{t+1}+\beta_{2} y_{t-1}-\varepsilon_{t}^{\mathrm{s}} \\
& A_{t}=\gamma_{1}\left(y_{t}+\varepsilon_{t}^{\mathrm{s}}\right)+\gamma_{2} E_{t} A_{t+1}-\left(i_{t}-E_{t} \pi_{t+1}\right)+\varepsilon_{t}^{\mathrm{e}} \\
& F_{t}=\gamma_{1}\left(y_{t}+\varepsilon_{t}^{\mathrm{s}}\right)+\gamma_{2} E_{t} F_{t+1}-\left(i_{t}-E_{t} \pi_{t+1}\right) \\
& \varepsilon_{t}^{j}=\rho_{j} \varepsilon_{t-1}^{j}+e_{t}^{j}, \quad j=\mathrm{d}, \mathrm{s}, \mathrm{e}
\end{aligned}
$$

Eq. (1) is the aggregate demand equation and, except for the asset price term, is derived in McCallum and Nelson (1999) from a dynamic general equilibrium model with optimising agents. We add an ad hoc term $\left(\alpha_{2} A_{t}\right)$ to incorporate a wealth effect. This is a shortcut within the spirit of the debate (see, e.g., Cecchetti et al., 2000). The difference to the demand shock, $\varepsilon^{\mathrm{d}}$, is that monetary policy observes asset prices. We set the coefficient $\alpha_{1}=0.6$ as in Estrella and Fuhrer (2002), and $\alpha_{2}=0.04$ following Bernanke and Gertler (1999).

Eq. (2) is a "hybrid" Phillips curve, where in face of the discussion and evidence provided in Galí and Gertler (1999), we have substituted lagged output for the marginal cost. $\varepsilon^{\mathrm{s}}$ is a "supply" shock. Following the survey of empirical estimates presented in Rudebusch (2002), we employ two levels of persistence: low $\left(\beta_{1}=0.4\right)$ and high $\left(\beta_{1}=0.9\right)$. We set $\beta=0.99$ as in Galí and Gertler (1999), and $\beta_{2}=0.3$ as in Rudebusch (2002). 
Eq. (3) is derived from a standard dividend model of asset pricing: it gives equity prices as a function of next-period dividends (assumed to depend on current output and the supply shock), expected future dividends (incorporated into the expected equity price, $E_{t} A_{t}+1$ ), and the real interest rate. Following Bernanke et al. (1999), we set $\gamma_{1}=0.5$ and $\gamma_{2}=0.97$. We add a disturbance $\left(\varepsilon_{t}^{\mathrm{e}}\right)$ which represents an equity premium shock of the type discussed in Cecchetti et al. (2000).

Eq. (4) gives the fundamental value of equities. It is the same as Eq. (3), except for the omission of the nonfundamental equity premium shock.

Eq. (5) defines the shocks in the system as first-order autoregressive processes. We allow for two degrees of persistence, low $\left(\rho_{j}=0.1\right)$ and high $\left(\rho_{j}=0.9\right)$. Given the lack of estimates in the literature (a hard task in view of the nonobservability of the equity premium shocks), the variance-covariance matrix of the innovations $\left(\varepsilon_{t}^{j}\right)$ is assumed to be the identity matrix.

The values of the parameters in the policy rule are chosen so as to minimise the following loss function (also used by, e.g., Rudebusch and Svensson, 1999):

$$
\text { Loss Function }=V\left(\pi_{t}\right)+V\left(y_{t}\right)+0.5 V\left(i_{t}-i_{t-1}\right)
$$

where $V(x)$ represents the unconditional variance of variable $x$.

Among the problems central banks face when reacting to asset prices is the estimation of misalignments. In this paper, we look at the implications of uncertainty in the estimation of misalignments. We introduce uncertainty in the model in the following way (which is similar to Aoki, 2003). We assume that the policymaker observes a noisy measurement of the variables that are included in the policy rule; that is, the actual policy rule is

$$
i_{t}=\delta_{1}\left(E_{t-1} \pi_{t+1}+n_{t}^{\pi}\right)+\delta_{2}\left(A_{t-1}-F_{t-1}+n_{t}^{A}\right)
$$

where $n_{t}^{\pi}$ and $n_{t}^{A}$ are serially uncorrelated noise processes. We will allow for different degrees of contemporaneous correlation between these noise processes, following the argument of Cecchetti et al. (2000) that errors in the estimation of inflation and asset price misalignments are likely to be correlated. The variances of the noise processes are assumed to be a fraction $n$ ("noise-to-signal ratio") of the variance of the variables to which they relate, i.e., $V\left(n_{t}^{\pi}\right)=n . V\left(\pi_{t}\right)$ and $V\left(n_{t}^{A}\right)=n . V\left(A_{t}-F_{t}\right)$. For simplicity and to keep the computational effort manageable, $n$ is equal for all processes. To solve our model, we employed the Schur decomposition as described in Soderlind (1999). We used the programs made available by Paul Soderlind at http:/www.hhs.se/personal/psoderlind.

In this setup, the computation of the variances is tricky, because the variance of the noise shocks depends on the variance of endogenous variables. We employed an iterative procedure. The solution of this type of model can be written as an $A R(1): \boldsymbol{x}_{t}=M \boldsymbol{x}_{t-1}+\boldsymbol{e}_{t}$, where $\boldsymbol{x}_{t}$ is the vector of endogenous variables and $\boldsymbol{e}_{t}$ is the vector of exogenous shocks. The variance of $\boldsymbol{x}_{t}$ satisfies:

$$
V^{x}=M V^{x} M^{\prime}+V^{e}
$$

In our model, the variance of $\boldsymbol{e}_{t}$ satisfies

$$
V^{e}=R_{0} V^{x}+R_{1}
$$


Table 1

The different parameterisations employed

\begin{tabular}{lllllllll}
\hline Case & (a) & (b) & (c) & (d) & (e) & $(\mathrm{f})$ & $(\mathrm{g})$ & $(\mathrm{h})$ \\
\hline$\beta_{1}$ & 0.4 & 0.9 & 0.4 & 0.9 & 0.4 & 0.9 & 0.4 & 0.9 \\
$\rho_{\mathrm{e}}$ & 0.1 & 0.1 & 0.1 & 0.1 & 0.9 & 0.9 & 0.9 & 0.9 \\
$\rho_{\mathrm{d}}, \rho_{\mathrm{s}}$ & 0.9 & 0.9 & 0.1 & 0.1 & 0.9 & 0.9 & 0.1 & 0.1 \\
\hline
\end{tabular}

$R_{0}$ relates the variances of the noise processes to those of the endogenous variables, while $R_{1}$ gives the variances of the other exogenous shocks. Given an estimate of the variances of $x\left(V_{0}^{x}\right)$ and $e\left(V_{0}^{e}\right)$, we update the estimates as follows:

$$
\begin{aligned}
& V_{1}^{x}=M V_{0}^{x} M+V_{0}^{e} \\
& V_{1}^{e}=B V_{1}^{x}+V e
\end{aligned}
$$

Eq. (6) is an inflation forecast-based rule (IFB), where the interest rate responds to expected inflation and to misalignments in asset prices. According to Bernanke and Gertler (1999), an inflation forecastbased rule that does not react to asset prices is the most adequate monetary strategy to deal with nonfundamental movements in asset prices. ${ }^{1}$ However, comparisons of the performance of different policy rules always bring to mind the "Lucas critique." The parameters in our model do not explicitly depend, as a result of how the model was derived, on policy rule parameters. Taking the possibility of a structural change into account would make the computations even harder and would require additional calibration assumptions. Besides, the purpose here is just to illustrate the consequences of adding noise to the policy variables, an important - although so far not modelled-element in this debate. Therefore, we chose to leave this issue for future research.

\section{Results}

We optimised the coefficients of the IFB rule under the different parameterisations employed (presented in Table 1). The optimisation was carried out via grid search, with a step length equal to 0.01 . Experimentation indicated that reducing the step length would affect the results only slightly, leaving the conclusions unchanged.

In most of the cases considered, reacting to misalignments in asset prices has little impact on the loss. Understandably, the exceptions arise when equity shocks are more persistent than demand and supply shocks, i.e., in cases $(g)$ and $(h)^{2}$

We computed (approximate) "critical" noise-to-signal ratios, i.e., the noise-to-signal ratio at which the coefficient corresponding to the reaction to asset prices becomes nonpositive. Given the computational effort involved, we did not compute the actual critical noise-to-signal ratio. Rather we optimised the coefficients of the policy rules for each level of correlation $(0.0,0.1, \ldots, 0.9)$ and for noise-to-signal ratios

\footnotetext{
${ }^{1}$ Previous versions of this paper also report results for a Taylor rule. Those results are similar but less clear-cut than the results presented here. Likewise, a larger $\alpha_{2}$ will increase the case for reacting to misalignments. These results are available from the authors upon request.

2 To save space, these results are not reported here but are available from the authors upon request.
} 
Table 2

Critical noise-to-signal ratio using the IFB rule and $\alpha_{2}=0.04$

\begin{tabular}{lllllllllll}
\hline Case & 0 & 0.1 & 0.2 & 0.3 & 0.4 & 0.5 & 0.6 & 0.7 & 0.8 & 0.9 \\
\hline (a) & NF & 0.1 & 0.1 & 0.1 & 0.1 & 0.1 & 0.1 & 0.1 & 0.1 & 0.1 \\
(b) & NF & 0.1 & 0.1 & 0.1 & 0.1 & 0.1 & 0.1 & 0.1 & 0.1 & 0.1 \\
(c) & NF & 0.2 & 0.1 & 0.1 & 0.1 & 0.1 & 0.1 & 0.1 & 0.1 & 0.1 \\
(d) & NF & 0.1 & 0.1 & 0.1 & 0.1 & 0.1 & 0.1 & 0.1 & 0.1 & 0.1 \\
(e) & NF & NF & NF & 0.7 & 0.5 & 0.4 & 0.3 & 0.3 & 0.2 & 0.2 \\
(f) & NF & NF & NF & 1 & 0.7 & 0.6 & 0.5 & 0.4 & 0.4 & 0.3 \\
(g) & NF & NF & NF & NF & NF & NF & 0.8 & 0.6 & 0.5 & 0.4 \\
(h) & NF & NF & NF & NF & NF & NF & NF & NF & NF & NF
\end{tabular}

NF: the coefficient of reaction to asset price misalignments was always positive.

The table shows the first noise-to-signal ratio $(n)$ for which the coefficient of reaction to asset price misalignments in the policy rule became nonpositive. The search was restricted to $n=0.1,0.2, \ldots 1.0$.

equal to $0.1,0.2, \ldots, 1.0$. For each level of correlation, the first noise-to-signal ratio for which the reaction coefficient is nonpositive is reported as being the critical noise-to-signal ratio. Table 2 presents the results.

Especially for high error correlation, the critical noise-to-signal ratio is very low in cases (a)-(d) and somewhat higher or even not found in the range $0.1, \ldots, 1.0$, in cases (e)-(h).

Introducing correlated noise in the estimation of the variables that enter the policy rule reduces the optimised value of the coefficient corresponding to the misalignment in asset prices. Depending on the value of the parameters in the model, this reaction coefficient may quickly become negative, thus contradicting the "lean against the wind" prescription. Empirical research on the degree of persistence and relative importance of different shocks is required to help discern which calibrations are plausible.

Nevertheless, it must be stressed that our model does not take into account the possibility that reacting to asset prices may by itself reduce the likelihood of significant misalignments occurring. If reacting (with a positive coefficient) to misalignments has this effect, then this benefit will have to be weighed against the consequences of positively correlated estimation errors.

\section{Acknowledgements}

The authors are grateful to John Driffill, Ron Smith, Peter Spencer, and participants at the CEPR Annual Workshop on Asset Prices and Monetary Policy, Helsinki, and the 9th International Conference of the Society of Computational Economics, Seattle, for helpful comments. We thank Eduardo Barata and Luís Cruz for helping with the computations. The usual disclaimer applies. Fernando Alexandre and Pedro Bação also acknowledge financial support from Fundação para a Ciência e a Tecnologia, grants Praxis XXI/BD/19895/99 and SFRH/BD/1076/2000, respectively. Enlarged versions of this paper were circulated under the title "Equity Prices and Monetary Policy: An Overview with an Exploratory Model".

\section{References}

Aoki, K., 2003. On the optimal monetary policy response to noisy indicators. Journal of Monetary Economics 50, $497-523$. Bernanke, B., Gertler, M., 1999. Monetary policy and asset price volatility. Federal Reserve Bank of Kansas City Economic Review 84, 17-51. 
Bernanke, B., Gertler, M., Gilchrist, S., 1999. The financial accelerator in a quantitative business cycle framework. In: Taylor, J.B., Woodford, M. (Eds.), Handbook of Macroeconomics vol. 15. North-Holland, Amsterdam, pp. 1341-1393.

Cecchetti, S.G., Genberg, H., Lipsky, J., and Wadhwani, S., 2000. Asset Prices and Central Bank Policy. International Center for Monetary and Banking Studies and CEPR.

Estrella, A., Fuhrer, J.C., 2002. Dynamic inconsistencies: counterfactual implications of a class of rational-expectations models. American Economic Review 92, 1013-1028.

Galí, J., Gertler, M., 1999. Inflation dynamics: a structural econometric analysis. Journal of Monetary Economics 44, $195-222$.

McCallum, B.T., Nelson, E., 1999. An optimizing IS-LM specification for monetary policy and business cycle analysis. Journal of Money, Credit, and Banking 31, 296-316.

Rudebusch, G.D., 2002. Assessing nominal income rules for monetary policy with model and data uncertainty. Economic Journal 112, 402-432.

Rudebusch, G.D., Svensson, L.E.O., 1999. Policy rules for inflation targeting. In: Taylor, J.B. (Ed.), Monetary Policy Rules. University of Chicago Press, Chicago, pp. 203-246.

Soderlind, P., 1999. Solution and estimation of RE macromodels with optimal policy. European Economic Review 43, 813-823. 